\title{
AVALIAÇÃO DAS ATIVIDADES DO BANCO DE OLHOS DA SANTA CASA DE PORTO ALEGRE 2003-2007
}

\author{
Activity of the Eyes bank at Santa Casa Hospital, Southern Brazil between 2003 and 2007
}

Veridiana Gobbi Michelon', Tatiana Michelon², Valter Duro Garcia', Alexandre Seminotti Marcon ${ }^{1}$

\begin{abstract}
RESUMO
Objetivo: Descrever a captação de córneas no Complexo Hospitalar Santa Casa de Porto Alegre (CHSCPA) e analisar as atividades do seu Banco de Olhos (BOSCPA) entre 2003 e 2007. Métodos: Análise retrospectiva da captação de córneas no CHSCPA e dos prontuários dos doadores de origem interna e externa atendidos pelo BOSCPA no período. Empregou-se teste t de Student ou Mann-Whitney, Qui-quadrado e descrição das taxas de porcentagem, sendo significativo $\mathrm{P}<0,05$. Resultados: Entre os 11398 óbitos registrados no CHSCPA, 29,5\% eram potenciais doadores e 10,6\% foram doadores efetivos. A não doação por contraindicação médica ocorreu em 51,9\% e a negativa familiar somou 49,6\%. O BOSCPA processou 3785 córneas de 2087 doadores (62,7\% captação interna e 37,3\% externa). Os doadores internos eram mais idosos, com óbito por neoplasia e menos comumente em morte encefálica. A taxa global de descarte das córneas processadas foi de 29\%, sendo $64 \%$ das córneas liberadas destinadas a transplante óptico e 36\% a enxerto tectônico. Conclusão: O CHSCPA obteve uma taxa de negativa familiar relativamente alta e uma baixa taxa de potenciais doadores, sendo seus doadores mais idosos e com óbito por neoplasia. O BOSCPA, com mais de $60 \%$ de seu atendimento procedente das captações internas, foi responsável por 54\% das captações e $22 \%$ dos transplantes corneanos do estado no período de estudo.
\end{abstract}

Descritores: Córnea, Transplante de Córnea, Obtenção de Órgãos e Tecidos, Doadores de Tecido, Coleta de Tecidos e Órgãos.

\footnotetext{
Instituições:

1 Banco de Córneas do Hospital Dom Vicente Scherer - Irmandade Santa Casa de Porto Alegre. Porto Alegre, Rio Grande do Sul.

2 Laboratório de Imunologia de Transplantes do Hospital Dom Vicente Scherer - Irmandade Santa Casa de Porto Alegre. Porto Alegre, Rio Grande do Sul.

${ }^{3}$ Comissão Intra-Hospitalar de Transplante de Órgãos e Tecidos - Irmandade Santa Casa de Porto Alegre. Porto Alegre, Rio Grande do Sul.
}

Correspondência:

Veridiana Gobbi Michelon

Rua Jacinto Gomes, 24/55 - CEP: 90040-270 - Porto Alegre/RS - Brasil

Tel.: (54) 32081727

E-mail: veri.gm@hotmail.com

Recebido em: 14.08 .2009

\section{INTRODUÇÃO}

A córnea é uma das estruturas oculares responsável pela transmissão e refração da luz que penetra no olho. ${ }^{1}$ Funciona como uma lente que, associada ao cristalino, compõe o sistema óptico responsável por focalizar as imagens na retina. ${ }^{2}$ A transparência da córnea é fundamental para a função visual e decorre da combinação de fatores como: distribuição regular das camadas corneanas, ausência de vasos, pouca hidratação, superfície epitelial lisa, pressão intra-ocular fisiológica, adequado filme lacrimal protetor e equilíbrio osmótico. ${ }^{3}$

A deficiência visual possui conseqüências sociais importantes, com impacto sobre a qualidade de vida global do indivíduo. O transplante de córnea constitui um dos mais antigos procedimentos oftalmológicos, fazendo parte da prática médica desde $1930 .{ }^{4}$ Este procedimento é capaz de propiciar a recuperação visual de um indivíduo com deficiência visual causada por patologias da córnea e sua reinserção na sociedade. Por esta razão, este é o tipo mais comum de transplante, entre todos os órgãos e tecidos enxertados com o objetivo de recuperação funcional. ${ }^{5}$ Assim como nos demais transplantes, a peculiaridade deste tipo de tratamento decorre da necessidade de obtenção do tecido responsável pelo restabelecimento da visão a partir de outro indivíduo proveniente da sociedade, neste caso, em óbito. ${ }^{6}$

O número de transplantes de córnea realizados na maioria dos serviços é ainda insuficiente para atender à demanda de pacientes em espera por 
este tratamento.? São realizados anualmente cerca de 40 mil cirurgias nos Estados Unidos, e aproximadamente 10 mil no Brasil. ${ }^{8}$

O Banco de Olhos da Santa Casa de Porto Alegre (BOSCPA) iniciou suas atividades oficialmente em 2003, a partir da sua regulamentação pelo Ministério da Saúde. Está instalado nas dependências do maior centro de transplantes da América Latina (Hospital Dom Vicente Scherer - Complexo Hospital Santa Casa) e segue os padrões internacionais, como também as nacionais, ou seja, o Regulamento Técnico Nacional de Transplante e a RDC (Resolução da Diretoria Colegiada) da ANVISA (Agencia Nacional de Vigilância Sanitária) para a captação e a preservação de córneas, baseados nas normas da Associação Panamericana de Bancos de Olhos (APABO) e da Associação Americana de Bancos de Olhos (EBAA). ${ }^{9,10}$

Devido à escassez de estudos sobre Bancos de Olhos no Brasil, o objetivo desde trabalho foi avaliar o perfil dos doadores captados na Santa Casa de Porto Alegre ou recebidos pelo banco de olhos e analisar o resultado das atividades do BOSCPA desde sua formalização até os dias atuais (2003 - 2007).

\section{MÉTODOS}

A avaliação das atividades do BOSCPA foi dividida entre a análise da captação de doadores de córneas dentro do Complexo Hospitalar Santa Casa e a análise dos doadores e das córneas de origem interna e externa atendidos por este banco.

\subsection{Logística do BCSCPA}

Atualmente a instituição Santa Casa realiza busca ativa de doações dentro do próprio complexo hospitalar e em hospitais públicos e privados, necrotérios e instituto médico-legal localizados na área de sua competência de atuação, conforme a legislação vigente.

O BOSCPA é responsável pelos processos de captação, remoção e processamento dos tecidos corneanos, enquanto, em conjunto com a Central de Notificação, Captação e Distribuição de Órgãos (CNCDO) do estado do Rio Grande do Sul, realiza a remoção e o processamento em quase todos os hospitais de Porto Alegre e da região metropolitana, além de processar globos oculares removidos em algumas cidades do interior do estado. Exceção é o Banco de Córneas do Hospital de Clínicas de Porto Alegre, responsável pela captação e processamento dos tecidos de doadores captados internamente no próprio hospital. O estado ainda conta com outros três bancos de olhos localizados no interior do Estado. ${ }^{8,11}$

Quando a doação ocorre dentro do Complexo Hospitalar Santa Casa, a notificação da doação segue um protocolo-padrão definido juntamente à Comissão Intra-hospitalar de Doação de Órgãos e Tecidos (CIHDOT). Cada potencial doador é notificado pelos funcionários do necrotério ao Serviço Social para que seja efetuada a entrevista familiar. Em caso de doação consentida, através da assinatura do termo de consentimento livre e esclarecido, a equipe do BOSCPA é acionada diretamente pelo entrevistador e se desloca ao necrotério, onde é realizado o procedimento de remoção do(s) globo(s) ocular(es).

Quando a captação ocorre em outros serviços de saúde, os responsáveis pela entrevista e notificação da doação à CNCDO são os membros da CIHDOT de cada hospital. Cada serviço tem seu próprio protocolo para notificação de potenciais doadores de córnea. Após o consentimento familiar, a equipe do BOSCPA é acionada pela $\mathrm{CNCDO}$, ou pelo próprio funcionário responsável de cada instituição, e se direciona ao local da remoção dos tecidos.

\subsection{Avaliação das Atividades do BCSCPA}

\subsubsection{Avaliação Intra-Institucional (interna):}

Realizou-se um estudo retrospectivo de todos os óbitos ocorridos na Santa Casa de Porto Alegre, avaliando-se os registros médicos constantes no necrotério institucional no período de janeiro de 2003 a dezembro de 2007.

Destes registros foram analisados: o número total de óbitos, o número de potenciais doadores (PD), o número de doadores efetivos (DE) e as causas de não-doação. Os casos de óbitos ocorridos na Santa Casa livres dos critérios de exclusão para a doação de córnea foram definidos como PD, restringindo-se, para fins do presente estudo, àqueles assim classificados após a avaliação da CIHDOT. Os doadores falecidos submetidos à remoção de globo(s) ocular(es) foram denominados DE. As causas de não-doação incluíram: negativa familiar, idade do doador fora dos limites pré-determinados e contra-indicação médica (CIM). Conforme regimento interno do BOSCPA, foram captados tecidos de doadores entre 2 e 80 anos e livres de qualquer CIM definida pela legislação vigente..$^{8,12}$

\subsubsection{Avaliação Global: Interna e Externa}

Além dos dados acima, foram avaliados os registros internos do BOSCPA com o objetivo de comparar as características demográficas e clínicas dos doadores internos e externos cujas córneas foram processadas neste mesmo período. Foram avaliadas as seguintes características: gênero, idade, procedência, causa da morte, doador em morte encefálica, tempo de enucleação e tempo de preservação da córnea.

A procedência do doador foi classificada em: interior do estado do Rio Grande do Sul, Porto Alegre, região metropolitana, outros estados brasileiros e outros países.

As causas do óbito foram classificadas em seis grupos, conforme o Código Internacional de Doenças (CID 10). A definição de doador em morte encefálica obedeceu aos critérios constantes na resolução do Conselho Federal de Medicina, número 1480/97. A análise desta característica do doador foi motivada pela inferência que representa sobre o sistema de captação de órgãos e tecidos do estado e pela importância do potencial orgânico de uma córnea removida ainda sob perfusão tecidual. ${ }^{14,15}$

O BOSCPA realizou captações em doadores até 6 horas após a parada cardiorrespiratória ou até 24 horas, nos casos de corpos mantidos sob refrigeração. O tempo de enucleação foi definido como o número de horas decorridas entre o óbito e a remoção dos globos oculares. O tempo de preservação foi calculado como o número de horas decorridas entre a retirada dos globos oculares e o processamento do tecido. ${ }^{8,12}$

\subsubsection{Avaliação Qualitativa do tecido corneano}

A decisão pela não-preservação da córnea ocorreu em dois momentos distintos: após a avaliação anatômica do globo ocular 
ou após a avaliação microscópica em lâmpada de fenda para a classificação final do tecido corneano em: excelente, bom, regular, ruim e inaceitável. As três primeiras categorias permitem que o tecido seja utilizado em enxertos para fins ópticos, com o objetivo de restabelecer a visão. Já os tecidos classificados como "ruins" são destinados a enxertos tectônicos com a função principal de preservar a estrutura corneana lesada após perda de tecido. Os tecidos considerados inaceitáveis são descartados. ${ }^{8,16}$ As causas anatômicas que contra-indicaram a preservação incluíram: colabamento, hipotonia, infiltrado estromal e/ou duplo pterígio. As causas microscópicas incluíram: edema, ceratite, reflexo especular, perda endotelial, corpo estranho, cirurgia prévia, infiltrado estromal. ${ }^{12}$

\subsubsection{Análise estatística}

Para a análise estatística, empregou-se o teste $t$ de Student ou Mann Whitney para as variáveis contínuas e o teste de quiquadrado para as variáveis categóricas. As taxas de prevalência foram descritas em percentagem e convertidas para taxas por milhão de população (pmp) e/ou pmp/ano. Foram considerados significativos valores de $\mathrm{p}<0,05$ e intervalo de confiança de 95 (IC95\%). Para este estudo, utilizou-se o software Statiscal Package for Social Sciences, versão 14.0.

\section{RESULTADOS}

\subsection{Avaliação Intra-Institucional (interna)}

Entre os anos de 2003 e 2007, ocorreram no Complexo Hospitalar Santa Casa de Porto Alegre 11398 óbitos. Deste total, foram excluídos pelo necrotério as causas universais que contraindicam a doação de órgãos (sorologia positiva e septicemia). O rastreamento de potenciais doadores pelo necrotério excluiu 2111 , representando $18,5 \%$ dos óbitos registrados. Foram elegíveis pela CIHDOT 3368 potenciais doadores (29,5\% do total de óbitos). A efetivação da doação ocorreu em 1212 casos, representando 10,6\% do total de óbitos registrados e $36 \%$ dos potenciais doadores.

$\mathrm{Na}$ avaliação das causas de não doação do tecido corneano, CIM foi identificada em 51,9\% (5919/9287) dos óbitos avaliados pela CIHDOT. Negativa familiar foi documentada em 49,6\% (1371/3368) dos potenciais doadores. A Figura 1 apresenta os resultados da captação de córneas na instituição no período de estudo.

Figura 1. Representação esquemática da atividade de captação intrainstitucional do BCSCPA entre 2003 e 2007.

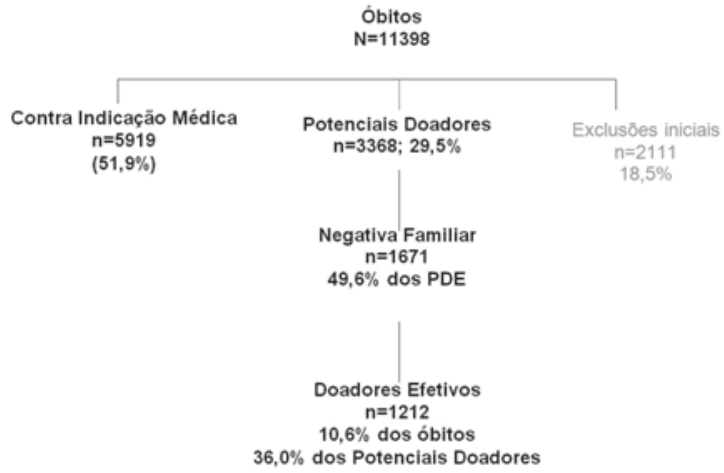

\subsection{Avaliação Global: Interna e Externa}

\subsubsection{Características dos Doadores}

Após a regulamentação do BOSCPA em 2003, foram captadas 3.785 córneas, a partir de 2.087 doadores, representando 208,7 doações de córnea pmp do estado do Rio Grande do Sul. No período de 2003 a 2007 os tecidos procedentes de captações realizadas na própria instituição representaram 62,7\% (n=1308) das doações atendidas, sendo as demais $37,3 \%(n=779)$ obtidas a partir de captações externas.

As doações foram mais freqüentes entre indivíduos do sexo masculino $(58,9 \%, 1229 / 2087)$, com predomínio significativo entre as captações externas comparadas às realizadas no próprio hospital (SC: 57\% x Externo: 62\%; $\mathrm{p}=0,026)$. A média de idade dos doadores de córnea foi 57,3+17,3 anos, sendo os doadores externos significativamente mais jovens do que aqueles captados na própria instituição (SC: 60,3 + 15,4 x Externo 52 + 19,0 anos; $\mathrm{P}=0,000$ ).

Na avaliação da procedência dos doadores, 50,9\% (n=1062) eram procedentes de Porto Alegre, representando 747,9 doadores de córnea pmp desta capital. A região metropolitana de Porto Alegre contribuiu com 653 doadores, representando 163,2 pmp, sendo esta a procedência de $30 \%$ dos doadores internos e externos, respectivamente. Doadores do interior do estado foram 353 no total, representando $78,4 \mathrm{pmp}$ desta região. Estes últimos constituíram 15,6\% dos doadores captados na Santa Casa de Porto Alegre e 19,1\% das captações externas atendidas pelo BOSCPA. Outros estados brasileiros contribuíram com 18 doadores $(0,9 \%)$ e houve um doador procedente do Uruguai nesta casuística.

As causas mais freqüentes de óbito entre os doadores de córnea estudados foram: neoplasia ( $n=875 ; 42,0 \%)$, doença cardiovascular $(n=629 ; 30,1 \%)$ e causas externas/trauma ( $n=226 ; 11,0 \%)$. Entre os doadores internos, neoplasia foi a causa do óbito de 58,5\% $(n=765)$, seguida por doença cardiovascular em 22,7\% ( $n=297)$,

doenças do aparelho respiratório em 8,2\% ( $n=108)$, causas externas/trauma $2,3 \%(n=31)$, outras causas em $3,5 \%(n=45)$ e ausência de registro em 4,7\% ( $n=62)$. Nos demais serviços de saúde captadores de córneas, a causa mais comum de morte foi doença cardiovascular ( $n=332 ; 43,0 \%)$, seguida por trauma ( $n=195$; $25,0 \%)$, neoplasia $(n=110 ; 14,1 \%)$, doença do aparelho respiratório ( $n=76 ; 9,7 \%)$, outras causas $0,9 \%(n=7 ; 0,9 \%)$ e ausência de registro $(\mathrm{n}=59 ; 7,6 \%)$, respectivamente.

Os doadores em morte encefálica eram mais jovens, geralmente doadores de múltiplos órgãos e tecidos. Constituíram 14,5\% $(\mathrm{n}=302)$ das doações corneanas, representando 7,1\% $(94 / 1308)$ das doações internas e 26,7\% (208/779) dos doadores externos $(\mathrm{p}=0,001 ; \mathrm{OR}=4,7[3,6-6,1])$.

\subsubsection{Avaliação das Córneas}

A mediana do tempo de enucleação foi de 3,2 horas, semelhante nas captações internas e externas $(\mathrm{p}=0,597)$. A mediana do tempo de preservação corneana foi de 1,7 horas, sendo 1,5 horas nos processamentos internos e 2,1 horas nos externos $(\mathrm{p}=0,001)$.

Entre os 2087 doadores, $89 \%(n=1857)$ tiveram ambas as córneas preservadas, 3,4\% $(n=71)$ apenas uma delas e 7,6\% tiveram suas córneas recusadas por problemas técnicos e/ou orgânicos.

A avaliação macroscópica da córnea contra-indicou a preservação de 389 delas (18,6\% do total de córneas removidas). Das 3785 
córneas avaliadas microscopicamente, 2,0\% $(n=75)$ foram classificadas como excelentes; $18,8 \%(n=711)$ como boas; $24,6 \%$ $(n=930)$ como regulares; $26,0 \%(n=983)$ ruins e $28,7 \%(n=1086)$ foram consideradas inaceitáveis. A classificação "inaceitável" nesta fase do processo incluiu, além das alterações microscópicas propriamente ditas $(n=546)$, as CIM $(n=540)$. Entre as CIM, sorologia reagente foi responsável por 408 exclusões de doação e ausência de sorologia (impossibilidade de coletar e examinar a amostra) por 66 delas, entre outras causas. Portanto, das 4174 córneas removidas, foram consideradas aceitáveis para o transplante 2699 (64,6\%), e sorologia reagente contra-indicou 19,5\% (408/2087) das doações. A distribuição de freqüência das sorologias reagentes observadas nesta série encontra-se descrita na Tabela 1.

Tabela 1. Freqüência de sorologias reagentes que contra-indicaram a doação de córnea

\begin{tabular}{lcc}
\hline Sorologia & $\mathbf{n}$ & $\mathbf{\%}$ \\
\hline anti-HIV & 11 & 0,5 \\
anti-HCV & 101 & 4,8 \\
HBsAg & 16 & 0,8 \\
anti-HBC & 280 & 13,4 \\
Total & $\mathbf{4 0 8}$ & $\mathbf{1 9 , 5 \%}$ \\
\hline
\end{tabular}

HIV: vírus da imunodeficiência adquirida

HCV: anticorpo dirigido contra 0 antígeno do core do vírus $C$ da hepatite

HBsAg: antígeno de superfície do vírus da hepatite B

HBC: anticorpo dirigido contra o antígeno do core do vírus B da hepatite

Tabela 2. Prevalância de descarte de córneas conforme a faixa etária

\begin{tabular}{|c|c|c|c|c|c|c|}
\hline Faixa Etária do Doador & $\mathbf{N}$ & Total & $\%$ & OR & IC & $\mathbf{P}$ \\
\hline$>40$ anos & 1270 & 3510 & 36,1 & 1,3 & $1,1-1,5$ & 0,003 \\
\hline Até 40 anos & 193 & 642 & 30,0 & & & \\
\hline$>50$ anos & 1112 & 2982 & 37,3 & 1,3 & $1,2-1,6$ & 0,000 \\
\hline Até 50 anos & 351 & 1170 & 30,0 & & & \\
\hline$>60$ anos & 812 & 2138 & 38,0 & 1,2 & $1,1-1,4$ & 0,000 \\
\hline Até 60 anos & 260 & 2014 & 48,0 & & & \\
\hline$>70$ anos & 459 & 1086 & 42,2 & 1,5 & $1,3-1,7$ & 0,000 \\
\hline Até 70 anos & 1004 & 3066 & 33,0 & & & \\
\hline
\end{tabular}

* qui quadrado

p: significancia estatística $(p<0,05)$

OR: odds ratio

IC: intervalo de confiança $95 \%$

A média de idade dos doadores cujas córneas foram descartadas após a avaliação macroscópica ou consideradas inaceitáveis posteriormente foi significativamente diferente (Aceitáveis: 51,7 $+17,9$ anos x Inaceitáveis: $61,5+15,7$ anos $p=0,000)$. A Tabela 2 descreve a prevalência de descarte de córneas conforme a faixa etária. A Tabela 3 demonstra as taxas de remoção e aproveitamento das córneas no estado do Rio Grande do Sul e na Santa Casa de Porto Alegre no período de estudo.

\section{DISCUSSÃO}

O estado do Rio Grande do Sul, com população de 10 milhões de habitantes, tem atualmente 1492 pacientes em lista de espera por
Tabela 3. Taxas de remoção e aproveitamento de córneas no Estado do $R S$ e $C H S C$

\begin{tabular}{lccc} 
Período 2003-2007 & N & pmp* & pmp/ano \\
\hline Rio Grande do Sul & & & \\
Córneas removidas & 7004 & 700,4 & 140,1 \\
Transplantes & 3109 & 310,9 & 62,2 \\
& & & \\
Santa Casa de Porto Alegre & & & \\
Córneas removidas & 3785 & 378,5 & 75,7 \\
Córneas distribuídas para transplante & 2699 & 269,9 & 54 \\
Córneas transplantadas & 697 & 69,7 & 13,9 \\
& & & \\
\hline
\end{tabular}

Fonte: Central de Transplantes do Rio Grande do Sul (CNCDO)

*pmp: por milhão de população do estado do Rio Grande do Sul (10 milhões de habitantes) RS: Rio Grande do Sul

CHSC: Complexo Hospitalar Santa Casa de Porto Alegre

um transplante de córnea. ${ }^{8}$ Esta demanda, extrapolada para os 5 anos analisados neste estudo, indica a necessidade de realização de 149 transplantes pmp/ano. Neste período, a CNCDO-RS registrou 140 remoções corneanas pmp/ano, sendo efetivamente transplantadas 44\% das córneas removidas (62 pmp/ano). ${ }^{11}$

A participação do BOSCPA ao longo deste período contribuiu isoladamente com $54 \%$ das córneas removidas no estado, o restante sendo realizado pelos outros quatro bancos existentes no estado. Este serviço disponibilizou para transplantes $71 \%$ das córneas por ele processadas, sendo 64\% destinadas a transplantes ópticos e 36\% para enxertos tectônicos. Entre as 3785 córneas processadas por este banco, apenas 18\% foram utilizadas clinicamente. Das córneas liberadas, $26 \%$ foram efetivamente utilizadas para transplantes, representando $22 \%$ de todos os transplantes corneanos realizados no estado entre os anos de 2003 e 2007.11 Dados isolados do ano de 2007 divulgados pelo Sistema Nacional de Transplante (SNT) informam que foram captadas 36,9 córneas pmp e implantadas 27,7 pmp em todo o país. Neste mesmo ano, no estado do Rio Grande do Sul (RS) foram captadas 204,4 córneas pmp e implantadas 68,4 pmp. Destas, 69,4\% foram captadas pelo BOSCPA. ${ }^{8,11}$

Desta forma, 400 córneas estão sendo liberadas anualmente pelo BOSCPA sem aproveitamento clínico. Isto representa uma taxa de 40 córneas pmp/ano que estão deixando de ser transplantadas. Considerando que a taxa anual de transplantes de córnea neste período supriu apenas $42 \%$ da necessidade, a otimização do uso das córneas disponibilizadas por este banco resultaria em um incremento significativo no número de transplantes de córnea no estado, passando de 62 para 102 pmp/ano. Esta taxa atenderia a $68,5 \%$ dos pacientes em lista de espera, ainda insuficiente para atender à demanda atual.

Os resultados observados a partir desta análise evidenciam que os serviços de captação e de processamento de córneas da Santa Casa atendem às necessidades internas e cumprem sua função de forma satisfatória. Nem mesmo uma taxa de negativa familiar, considerada elevada quando comparada às taxas de negativa de doação de órgãos e mesmo de doação de córneas em outros estados do país, comprometeu as atividades a que se propôs a instituição a partir da implementação da CIHDOT e do BOSCPA. ${ }^{17}$

Conforme dados do primeiro semestre de 2008 do Registro Brasileiro de Transplantes, a taxa de negativa familiar para 
a doação de órgãos no RS é de $29 \%$. $^{7}$ No entanto, a taxa de negativa familiar para a doação de córnea na Santa Casa de Porto Alegre atingiu 50\% entre os potenciais doadores de córnea. Em locais como Barcelona, esta taxa é tão baixa quanto $4 \%{ }^{18}$ Aspectos importantes relacionados a não-doação das córneas incluem o nível sócio-econômico e educacional da família, a relação de parentesco e a idade do falecido, a preocupação com a estética do doador, além da utilização da negativa como uma forma de manifestar sua insatisfação com o atendimento intrahospitalar. ${ }^{19,20}$

Em todo o país, o modelo de captação vigente, é o reconhecido "modelo espanhol", em nossa instituição foi possível estruturar o funcionamento da CIHDOT em turno integral (24 horas). Esta medida foi implantada para que todos os óbitos ocorridos durante os turnos vespertino, noite e finais de semana recebam atendimento especializado e garanta-se com isso, a otimização do processo de captação interna. Embora a estimativa de potenciais doadores de córnea entre todos os óbitos seja de 37\%, a instituição, por seu caráter terciário de atendimento em saúde, tem com essa medida, uma perspectiva de aumento do consentimento familiar, porém menos provavelmente de aumento da taxa de potenciais doadores. ${ }^{21}$

A taxa global de descarte de córneas de $35 \%$ por causas macro/ microscópicas e/ou por contra-indicação médica é um índice aceitável para o CHSCPA, apesar de taxas mais baixas serem descritas na literatura. ${ }^{22}$ Isto porque a instituição contribui com mais de $60 \%$ das córneas processadas pelo BOSCPA e esta é uma entidade eminentemente voltada para o atendimento de alta complexidade em doenças crônicas.

Este fato foi evidenciado pelas características dos doadores captados internamente, sendo eles mais idosos, com óbito decorrente de neoplasia e, menos freqüentemente, doadores de múltiplos órgãos.

A idade mínima e máxima de um doador para utilização do tecido varia conforme as normas médicas de cada banco de olhos. A idade avançada costuma ser um fator limitante, uma vez que a maioria dos cirurgiões prefere não utilizar córneas de indivíduos acima de 75 anos. ${ }^{23,24}$ Essa idade é arbitrária, pois embora a idade do doador não esteja relacionada com a sobrevida do enxerto corneano, há trabalhos que relatam uma associação entre a idade e a incidência de processos de rejeição. ${ }^{25}$ A condição endotelial é um dos fatores que determinam a aceitabilidade da córnea para o transplante. ${ }^{26}$

Apesar de os resultados do BOSCPA indicarem uma maior taxa de descarte das córneas quanto maior a idade do doador, somente um estudo sobre o destino das córneas disponibilizadas para transplante poderá auxiliar na análise do custo-benefício de se manter o programa de remoção em idades mais avançadas. Até então, a manutenção da estratégia atual pode ser sustentada pelo fato de a população aumentar a sua expectativa de vida nas últimas décadas, o que traz consigo também um aumento da necessidade de transplantes corneanos. ${ }^{24,27} \mathrm{Na}$ atualidade, doadores de córnea acima dos 55 anos constituem a maioria em grande parte dos centros do mundo. ${ }^{24,28}$ Todavia, não menos importante é o cuidado para com as particularidades oculares associadas a uma faixa etária elevada, os quais devem ser exaustivos quando se considera a utilização destas córneas para transplante.
O fato de a maioria de doadores captados na Santa Casa de Porto Alegre, ser portadora de neoplasia, não implica que suas córneas sejam de menor qualidade ou de maior risco. O tecido corneano removido destes indivíduos pode ser utilizado de forma segura para transplante, uma vez que a incidência de metástases oculares é da ordem de $1 \%$ entre os portadores de malignidade ativa e o risco de transmissão considerado inexistente. ${ }^{29}$ É interessante observar também que, assim como ocorre com os transplantes de órgãos sólidos, a condição clínica de doadores em morte encefálica, podendo ter vários de seus órgãos transplantados, garante a melhor qualidade dos tecidos enxertados. Isto pode ser comprovado pela menor taxa de descarte de córneas pelo BOSCPA entre os doadores de múltiplos órgãos.

A taxa de CIM entre todos os óbitos registrados na Santa Casa no período de 5 anos foi de 52\%, discretamente inferior à taxa de $60 \%$ apontada até o ano de $2005 .{ }^{4}$ A principal CIM para o aproveitamento da córnea doada foi a evidência de padrões sorológicos inadequados ou impossibilidade de avaliação do mesmo, sendo responsável pelo descarte de 20\% das córneas removidas. Nesta série, apenas $14 \%$ do total de córneas processadas pelo banco foram excluídas por CIM, refletindo a importância do rastreamento inicial realizado pelos demais serviços de captação cujas córneas são processadas pelo BOSCPA.

Igualmente importante na avaliação do processo de captação e de processamento das córneas pelo banco é a agilidade com que se procede à remoção e ao respectivo preparo do tecido. A observação da brevidade destas etapas é determinante para a preservação da vitalidade e da qualidade do tecido corneano. ${ }^{30}$ Apesar disto, alguns estudos não associam os tempos de enucleação e de preservação a um maior risco de falência do enxerto. ${ }^{31} \mathrm{O}$ BOSCPA conseguiu atingir o mesmo tempo de enucleação nas captações internas e externas e, embora significativamente mais prolongado, a diferença de menos de uma hora no tempo de preservação das córneas captadas externamente é improvável que comprometa a viabilidade do tecido no intervalo de tempo praticado.

Contrastando com os resultados apresentados pelo BOSCPA, um estudo semelhante, incluindo 13 anos de atividade conduzido na Nova Zelândia, demonstrou uma taxa de utilização para enxertia de $79 \%$ das córneas captadas. ${ }^{22}$ Os dados apresentados pelo BOSCPA não permitem inferir a causa da sub-utilização das córneas disponibilizadas para transplante, nem mesmo a possibilidade desta análise diferenciando a necessidade e a utilização das respectivas córneas para fins ópticos ou tectônicos, necessitando estudos específicos. Por ser a maior parte da sua captação de origem interna, ou seja, da própria instituição, as córneas são provenientes de indivíduos mais idosos, portadores de doenças crônicas. Uma maior demanda de córneas ópticas pela CNCDO justificaria, pelo menos em parte, a subutilização das córneas disponibilizadas pelo BOSCPA no período analisado.

\section{CONCLUSÃO}

Concluímos que a taxa de negativa familiar para a doação de córneas no CHSCPA é elevada e seus doadores são mais idosos e com óbito decorrente de neoplasia. A atividade global do BOSCPA tem sido eficiente no processamento e disponibilização de córneas para transplante, podendo-se ainda otimizar a captação interna e externa bem como a utilização clínica dos tecidos. 


\section{ABSTRACT}

Purpose: To describe the cornea procurement at the Porto Alegre Santa Casa Hospital (CHSCPA), and to analyze its Eyes Bank (BOSCPA) activity between 2003 and 2007. Methods: Retrospective analysis of the cornea procurement at the CHSCPA and the medical records of internal and external donors assisted by BOSCPA during that period. There were applied t'Student test or Mann-Whitney, Qui-square and rates description by percentage, being significant $\mathrm{P}<0.05$. Results: Among the 11398 deaths registered in the CHSCPA, 29.5\% were potential donors and $10.6 \%$ of them became effective corneal donors. Medical contra-indication occurred in 51.9\%, and familiar non-consentient for donation was $49.6 \%$. The BOSCPA processed 3785 corneas from 2087 donors $(62.7 \%$ internal and $37.3 \%$ external). The internal donors were older and dead due to neoplasia. The global refusal rate was $29 \%$ among processed tissues, being $64 \%$ of the corneas suitable for optical transplants and 36\% for tectonical grafts. Conclusion: The CHSCPA had a relatively high familiar refusal and low potential donor rates, being its donors older and with malignant diseases. The BOSCPA, with more than $60 \%$ of its activity related to the internal donors, comprised $54 \%$ of the cornea procurement and $22 \%$ of the transplants performed in the state during this period.

Keywords: Cornea, Corneal transplantation, Tissue and Organ Procurement, Tissue Donors, Tissue and Organ Harvesting.

\section{REFERÊNCIAS}

1. Sobotta J. Atlas de Anatomia Humana. Rio de Janeiro: Guanabara Koogan; 2006.

2. Kanski JJ. Oftalmologia Clínica - Uma Abordagem Sistêmica. São Paulo: Elsevier, 2004.

3. Marcon IM, Costa AJ, Seminotti N, Marcon AS. Transplante de córnea. In: Neumann J, Abud FM, Garcia VD, editores. Transplante de órgãos e tecidos. São Paulo: Sarvier; 1997. p. 336-52.

4. Barbosa AP, Pereira RCP, Garcia CD, Garcia VD. Project of Córnea Donation in the Hospital Complex of Santa Casa de Porto Alegre. Transplant Proc. 2007;39:341-3.

5. Junior BCO, Garcia PPC, Silva FM. Projeto de captação de córneas para transplante: experiência em um hospital geral. J Bras Transpl. 2005;8:296-8.

6. Moreno GL, Souza LB, Freitas D, Sato EH, Vieira LA. Transplante de córnea e o conhecimento do procedimento pelos pacientes. Arq Bras Oftalmol. 2003;66:797-801.

7. ABTO. Associação Brasileira de Transplante de Órgãos. [homepage na internet]. Brasil: [acesso em: 14 Out 2008]. Disponível em: http://www.abto/rbt.org.br

8. MINISTÉRIO DA SAÚDE. [homepage na internet]. Brasil: [acesso em: 10 Out de 2008]. Disponível em: http:// www.saude/snt.org.br

9. APABO. Associação Pan Americana de Banco de Olhos. [homepage na internet] Brasil: [acesso em: 10 Out de 2008] Disponível em: http://www.apabo.com.br

10. EBAA. Eye Bank Association of America. [homepage na internet]. EUA. [acesso em: 10 Out de 2008]. Disponível em: http://www.restoresight.org

11. CNCDO_RS.Central de Transplantes do Rio Grande do Sul. [homepage na internet]. Brasil: [acesso em 03 de Nov de 2008]. Disponível em: www.Saúde/cndco.rs.gov

12. Regimento Interno do Banco de Córneas da Santa Casa de Porto Alegre 2003 revisado em 2006, não-publicado, disponível para pesquisa nas dependências do mesmo ( $7^{\circ}$ andar, Hospital Dom Vicente Scherer, Complexo Hospitalar Santa Casa de Porto Alegre).

13. Organização mundial da saúde. CID-10: Classificação Estatística Internacional de Doenças e Problemas Relacionados a Saúde. São Paulo. Edusp, 2007.

14. CREMERS. Conselho Regional de Medicina. [homepage na internet]. Brasil: [acesso em: 03 de Out de 2008]. Disponível em:http://www.cremers/legislação.org.br

15. Garralda A, Epelde A, Iturralde O, Compains E, Maison C, Atarriba M, et al. Córnea Transplant. An Sist Sanit Navar. 2006;29(Supl. 2):163-74.

16. Medina JO, Sampaio EM, Santos TH, Aoqui CM, Ammirati AL, Caron D, et al. Deceased organ donation in Brazil: how can we improve? Transplant Proc. 2007;39(2):401-2.
17. Muraine M, Toubeau D, Menguy E, Brasseur G. Analysing the varions obstacles to cornea postmortem procuremet. J Bras Oftalmol. 2002;86:864-8.

18. Krieglstein TR, Neubauer AS, Welge-Lüssen U, Priglinger S, Kampik A, Priemer F. Cornea donation. Factors influencing consent. Graefes Arch Clin Exp Ophthalmol. 2002;240:816-21

19. Lawlor M, Dobbins T, Thomas KA, Billson F. Consent for corneal donation: the effect of age of the deceased, registered intent and which family member is asked about donation. J British of Ophthalmol. 2006;90:1383-5

20. Geissler A, Paoli K, Maitrejean C et al - Rates of potential and actual cornea donation in a general hospital: impact of exhaustive death screening and surrogate phone consent. Transplant Proc. 2004;36:2894-5.

21. Patel HY, Brookes NH, Moffatt L, Sherwin T, Ormonde S, Clover GM, et al. The New Zealand National Eye Bank Study 1991-2003: A Review of the Source and Management of Corneal Tissue. Cornea. 2005;24:576-82.

22. Farge EJ, Cox WG, Khan MM. An eye-banking program for selecting donor corneas for surgical distribution. Cornea. 1995;14(6):578-82

23. Adán DBC, Diniz RA, Perlatto D, Hirai EF, Sato HE. Dez anos de doação de córneas no Banco de Olhos do Hospital São Paulo: perfil dos doadores de 1996 a 2005. Arq Bras Oftalmol. 2008;71(2):176-81.

24. Trigui A, Smaoui M, Masmoudi J, Mhiri W, Maatoug S, Feki J. Corneal graft rejection: donor and receiver implication. J Fr Ophtalmol. 2005;28:631-4.

25. Lass JH, Ruedy KJ, Benetz BA, Beck RW, Baratz KH, Holland EJ, et al. An evaluation of image quality and accuracy of eye bank measurement of donor cornea endothelial cell density in the Specular Microscopy Ancillary Study. Ophthalmol. 2005;112(8):1394.

26. IBGE. Instituto Brasileiro de Geografia e Estatística. [homepage na internet]. Brasil: [acesso em: 03 Nov de 2008]. Disponível em: http:// www. ibge.gov.br

27. Moyes AL, Holland EJ, Palmon FE, Dvorak JA, Doughman DJ. Tissue utilization at the Minnesota Lions Eye Bank. Cornea. 1995;14(6):571-7.

28. Lopes NA, Soler N, Caballero F, Lerma E, Gris O. Corneal transplantation fron donors with câncer. Transplantation. 2007;27;83(10):1345-50.

29. Van Meter WS, Katz DG, White H, Gayheart R. Effect of death-to-preservation time on donor corneal epithelium. Trans Am Ophthalmol Soc. 2005;103:209-22.

30. Hirai EF, Klatte S, Pacini MK, Sato HE. Falência primária pós transplante de córnea em serviço universitário. Arq Bras Oftalmol. 2002;65:655-7. 